RESEARCH LETTER

\section{Cross country variation of fractures in the childhood population. Is the origin biological or "accidental"?}

EDIToR,-The interesting paper by Lyons et al revealed that the annual incidence rate of fractures among children aged $0-12$ years was two to three times higher in Wales ${ }^{1}$ than in other western European countries. ${ }^{2}{ }^{3}$ This discrepancy prompted us to briefly report on the epidemiological profile of fractures in the childhood population of Greece and discuss the implications of the observed differences.

Our data derive from the Emergency Department Injury Surveillance System (EDISS) database which is run by the Center for Research and Prevention of Injuries among the Young (CEREPRI). ${ }^{4}$ All types of childhood injuries treated at the emergency departments of the participating hospitals, which have well circumscribed catchmen areas in rural and urban Greece, are routinely recorded in this database. The catchment area includes the Greater Athens area, where about $40 \%$ of the country's population resides, Magnesia county in Greece mainland, and Corfu county on the island of Corfu. Our methodology was similar to that followed by Lyons et al thus allowing for reasonable comparisons.

A total of 8557 fractures were recorded during the three year period 1996-98 among children $0-14$ years old and the estimated annual incidence rate was 12 fractures/1000 children. No significant variation was noted among children from the different sites participating in EDISS. This rate is just one third of that recorded in the Welsh childhood population. In line with what is reported by Lyons et al, ${ }^{1}$ and other investigators, ${ }^{23}$ boys were also over represented in the Greek data set (male to female ratio: 1.9) and this preponderance increased with age. Altogether $2.7 \%$ of the injured children presented with multiple fractures, a figure that is higher than that reported by Lyons et al $(1.8 \%)$ and may be due to the high road traffic injury toll in Greece. In fact, one third of the multiple fracture injuries were the result of a road traffic crash, whereas traffic accidents accounted for less than $5 \%$ among injured children with one fracture.

The distribution of children by injured body part was comparable to that of the Welsh population, with fractures of radius and ulna accounting for $43 \%$ of the total, followed by fractures of fingers (13.9\%), humerus $(6.9 \%)$, and carpal/metacarpals $(4.8 \%)$. The similarity in the pattern of fractures among children who sought emergency hospital care in the two countries can be considered as an indicator of the high quality registration system in both sites and enhances the possibility that the observed difference of the fracture incidence rate is genuine. It is worth noting, however, that despite the low overall incidence of fractures in the Greek childhood population, the proportion of skull fractures was more than twice as high as that reported in the Welsh ${ }^{1}$ and in a related Swedish study. ${ }^{3}$ Cycle helmet use may not be optimal in the $\mathrm{UK}^{56}{ }^{56}$ but according to data derived from EDISS, use of protective devices for road traffic injuries is unacceptably low, and playgrounds do not usually comply with international standards. Therefore, the underlying causes for the discrepancy in skull fracture incidence should be carefully monitored in Greece, whether it is caused by reluctance to wear helmets or otherwise, and corrective action taken.

One third of the recorded fracture injuries in both studies occurred in residential areas, where children spend most of their time, followed by school areas and public premises. An average of $40 \%$ of fractures resulted from sports and leisure activities. Cultural differences and different sports and leisure time preferences between the two population groups, however, become obvious when the injuries are further analyzed by type of sport activity. Thus, ball related injuries were dominant in our population $(70 \%$ of sports related injuries among Greek compared with $40 \%$ among Welsh children), whereas wheeled sports activities were almost twice as common in Welsh compared with Greek children (35\% and $20 \%$ respectively).

In conclusion, comparison of data from these studies indicate that the incidence of fractures in the Greek childhood population is similar to that observed in Sweden but much lower than that reported by Lyons and his colleagues in Wales. The question is: could this variation simply be attributed to different exposure levels and/or different prevention strategies that are followed in the respective countries, or does it reflect the expression of a biological mechanism, possibly related to nutritional factors, ${ }^{7}$ that accounts for fewer Greek children suffering from fractures. The latter hypothesis cannot be properly addressed, however, without careful consideration of differences in data collection, coding, and processing methods. To test this hypothesis, comparative, population based crude and fracture specific injury incidence data among children from southern and northern European countries could be used to elucidate whether the observed differences simply reflect a corresponding difference in all-injury incidence or whether they are mainly related to differences in the incidence of fractures. If the latter is the case, further investigation focusing on possible differences of bone mass density or dietary intake should be considered in the interpretation of the observed variation of fractures on different population groups

M MOUSTAKI $M$ LARIOU

Department of Hygiene and Epidemiology, Athens University Medical School, Greece

E PETRIDOU

Department of Hygiene and Epidemiology, Athens University Medical School, 75 Mikras Asias, Goudi, Athens 115-27, Greece Department of Epidemiology,

Harvard School of Public Health, Boston, USA

Correspondence to: Dr Petridou in Athens

epetrid@cc.uoa.gr

1 Lyons RA, Delahunty AM, Kraus D, et al. Children's fractures: a population based study. $I n j$ Prev 1999;5:129-32

2 Kopjar B, Wichizer TM. Fractures among children: incidence and impact on daily activities. Inj Prev 1998;4:194-7.

3 Landin LA. Epidemiology of children's fractures. F Pediatr Orthop 1997;6(part B):79-83.

4 Petridou E Simou E Skondras $C$, et al . Hazard of baby walkers in a European context. Inj Prev 1996;2:118-20.

5 Wardle S, Iqbal Z. Cycle helmet ownership and wearing; results of a survey in South Staffordwearing; results of a survey in South Sta

6 Cryer PC, Cole J, Davidson LL, et al. Rates of, and the factors affecting, cycle helmet use among secondary schoolchildren in East Sussex and Kent. Inj Prev 1998:4:106-10.

7 Petridou E, Karpathios T, Dessypris N, et al. The role of dairy products and not alcoholic beverages in bone fractures among schoolage children. Scand $\mathcal{F}$ Soc Med 1997;25:119-25.

LETTERS TO
THE EDITOR

Speed reductions, inequalities, and transport

EDIToR,-We read the editorials in the BMF and Injury Prevention about speed limits with interest ${ }^{12}$ and would like to share some of the Scottish experience on speed reduction.

Councils throughout Scotland are conducting trials of advisory $20 \mathrm{mph}$ limits as part of a Scottish Executive initiative. In Lothian these are generally in residential areas and often linked with Safe Routes to Schools projects run by the councils in partnership with Lothian Safe Routes, SPOKES (an Edinburgh based cycle group), Lothian Health, and the police. In addition a small number of mandatory $20 \mathrm{mph}$ zones exist, with proposals in Edinburgh for a city wide $20 \mathrm{mph}$ limit in residential areas and on shopping streets.

Road traffic accidents (RTAs) are not spread evenly across communities, with disadvantaged children having a much worse experience of RTAs. ${ }^{3}$ In Edinburgh the City of Edinburgh Council has made traffic calming measures in areas with high accident rates a feature of the city's road safety strategy since the early 1990s. These have been mainly engineering measures to calm traffic in more disadvantaged parts of the city. This has resulted in a reduction in speeds and a $39 \%$ reduction in reported accidents in areas calmed under the "casualty reduction" programme (compared with 29\% reduction where "environmental traffic management" was the aim and $4 \%$ reduction where measures were in connection with bus priority routes). This is against a picture of relatively stable accident levels in the council area during the 1990s. This suggests that targeting areas with high accident levels can produce good results and ties in with other Scotland wide data (where increased walking and cycling was also demonstrated).

Engineering measures are costly, with the council spending some $£ 1.2$ million for the "casualty reduction" programme. While it remains to be seen whether the much less expensive advisory $20 \mathrm{mph}$ schemes will be of similar benefit, there are some lessons about implementing and enforcing these schemes. As these $20 \mathrm{mph}$ schemes are merely advisory, they can only be enforced if motorists are driving dangerously. Anecdotal evidence from early $20 \mathrm{mph}$ schemes suggest that, while speeds are in general reducing, a significant proportion of motorists have not moderated their speed. These motorists are often local residents who believe they "know the road" (Lothian and Borders Police, personal communication). This emphasises the importance of community consultation before schemes are introduced and regular feedback to the community after they are in place - in Scotland only around a third of 
residents have rated the consultation as sufficient. Where there is good consultation there is also a high level of satisfaction with the scheme put in place.

The Scottish Needs Assessment Programme (SNAP) has recently conducted a health impact assessment of Edinburgh's transport policy which endorses the council's transport policy as a means to promote social inclusion and reduce inequalities. ${ }^{6}$ The policy supports less reliance on cars and promotes walking and cycling, development of excellent public transport, and integrated land use policies for commercial and residential development.

D GORMAN

Public Health Medicine, Lothian Health, 148 The Pleasance, Edinburgh EH8 9RS, UK dermot.gorman@lhb.scot.nhs.uk

M DOUGLAS

Public Health Medicine, Lothian Health

P NOBLE

City of Edinburgh Council

1 Pless IB. Killing speed. Inj Prev 2000;6:163-6. 2 Pilkington P. Reducing the speed limit to $20 \mathrm{mph}$ in urban areas. BMY 2000;320:1160.

3 Roberts I. Does the decline in child injury mortality vary by social class? A comparison of class specific mortality in 1981 and 1991. BMF 1996;313:784-6.

4 Gorman DR, Ramsay LJ, Bull M, et al. Uptake of the children's traffic club in Lothian. Health Bulletin 2000;58:58-62.

5 Ross Silcock Limited/Social Research Associates. Community impact of traffic calming schemes: development department research programme research findings No 68. Edinburgh: Research Unit, 1999. impact assessment of the City of Edinburgh Council's urban transport strategy. Glasgow: SNAP, 2000.

A version of this letter was published in the BMF on 6 January 2001 (Gorman D, Douglas M, Noble P, et al. Both advisory and mandatory speed limits are being introduced in Edinburgh. BMf 2001;322:51).

\section{Population preventable fraction of bicycle related head injuries}

EDIToR,-The article by Dr Kopjar in a recent issue of the journal discussing the use of the population preventable fraction concerning bicycle related head injuries and helmet use was very interesting. ${ }^{1}$ Dr Kopjar uses the odds ratio (OR), obtained from casecontrol studies of the effectiveness of bicycle helmet use to prevent head injury, to provide an estimate of the relative risk (RR) required in the formula for the population attributable fraction. In the article, Dr Kopjar stated that "Incidence of head injuries is low, suggesting that these ORs can be used as a valid proxy for the RR". ${ }^{1}$ This point deserves further comment. There are two distinct types of case-control studies: the incidence density type and the cumulative incidence type. We
6 Scottish Needs Assessment Programme. Health

may assume an underlying cohort for each type from which cases and controls are sampled. The primary difference between the incidence density and cumulative incidence case-control studies is how we view the cohort and what information the control group provides. The incidence density casecontrol study views the underlying cohort as being stable and dynamic. The control group in an incidence density case-control study is intended to provide an estimate of the fraction of population time exposed and unexposed. The OR, then, is a ratio of pseudorates and provides an unbiased estimate of the incidence rate ratio, with no rare disease assumption (table 1). ${ }^{2}$ Thus it does not matter whether the disease is rare, only that controls be selected independently of exposure status to be representative of the distribution of the exposure in the source population which produced the cases. ${ }^{3}$

The cumulative incidence case-control study is where the rare disease assumption is important. The cohort underlying the cumulative incidence case-control study should be thought of as closed and fixed. Incident cases are sampled throughout a defined time period and controls are residual non-cases (that is, those individuals at risk who did not become cases over this period). In this situation, the control group does not provide a representation of person time. Instead, the relationship between the odds and the risk is what is key. That is, when the disease is rare, the odds of disease (cases/non-cases) and the risk of disease (cases/total at risk) are approximately equal (keeping in mind that the odds of disease is not available from a case-control study, only the OR):

Risk $=10$ cases $/ 1000$ total at risk $\approx 10$ cases $/(1000$ total at risk -10 cases $) \approx 10$ cases $/ 990$ non-cases $\approx$ odds

The case-control studies that provide the OR estimates used in Dr Kopjar's article could be seen as the incidence density type. The OR would then provide an unbiased estimate of the incidence rate ratio, with no rare disease assumption.

B HAGEL J-F BOIVIN

foint Departments of Epidemiology and Biostatistics and of Occupational Health, McGill University, 1020 Pine Avenue West, Montreal, $P Q$ H3A 1A2, Canad a bhagel@po-box.mcgill.ca

1 Kopjar B. Population preventable fraction of bicycle related head injuries. Inj Prev 2000;6:235-8.

2 Rothman K, Greenland S. Modern epidemiology. 2nd Ed. Philadelphia, PA: Lippincott-Raven, 1998: 738

3 Wacholder S, McLaughlin JK, Silverman DT, et al. Selection of controls in case-control studies. I. Principles. Am F Epidemiol 1992;135:101928.

4 Thompson DC, Rivara FP, Thompson RS. Effectiveness of bicycle safety helmets in preventing head injuries: a case-control study. fAMA 1996;276:1968-73.

Table 1 Hypothetical example of how the odds ratio is an unbiased estimate of the incidence rate ratio in an incidence density case-control study. The sampling fraction for cases is $10 \%$ and the control group provides the estimate of the fraction of person-time exposed and unexposed. This example is based on data from Thompson et $a l^{4}$

\begin{tabular}{|c|c|c|c|c|}
\hline Hypothetical cohort & Helmet & No helmet & Total & Incidence rate ratio \\
\hline $\begin{array}{l}\text { Cases } \\
\text { Bicycle riding hours }\end{array}$ & $\begin{array}{l}2220 \\
149554\end{array}$ & $\begin{array}{l}5350 \\
113746\end{array}$ & $\begin{array}{l}7570 \\
263300\end{array}$ & $(2220 / 149554) /(5350 / 113746)=0.316$ \\
\hline \multicolumn{4}{|c|}{ Incidence density sampling from the population experience: } & \\
\hline $\begin{array}{l}\text { Cases } \\
\text { Controls }\end{array}$ & $\begin{array}{l}222 \\
1496\end{array}$ & $\begin{array}{l}535 \\
1138\end{array}$ & $\begin{array}{l}757 \\
2634\end{array}$ & $\begin{array}{l}\text { Odds ratio } \\
(222 / 1496) /(535 / 1138)=0.316\end{array}$ \\
\hline
\end{tabular}

\section{BOOK REVIEW}

Undertaking Qualitative Research: Concepts and Cases in Injury, Health and Social Life. By J Peter Rothe. (Pp 224, paperback; C\$29.95). Edmonton, Canada: University of Alberta Press, 2000. ISBN 0-88864-367-5.

This book is an important contribution to the field of accident and injury research. It is a book for newcomers to qualitative research and as such would be an excellent key text for teaching. The book outlines a range of qualitative research methods and builds this into an appreciation of the theoretical underpinnings that favour one method more than another. Beyond pure methods and theory, the book conveys the realities of planning, undertaking, and finishing a research project.

The initial chapter "injury and the disclosure of the truth" is particularly compelling as it guides us into the minds of those who engage in qualitative research; those seeking "the insider perspective on injury" ( $p$ xviii). For qualitative researchers there is "no ultimate truth" ( $\mathrm{p}$ xix) but a series of constructed relationships grounded in cultural and social phenomenon.

Impressively, it addresses the issue of analyzing and writing up the research - an area often ignored in methodological texts. We are given the opportunity to look over a raw transcript and to do so again with the coding categories present. This is invaluable to first timers unsure of how to deal with huge bodies of interview transcripts and how to present these data after analysis.

Where the book could be stronger is in the decision to cover many methods briefly, as opposed to a few methods in greater detail. This trade off can be forgiven as it is an introductory book and contains suggestions for further reading about each method.

The inclusion of certain methods, or what Rothe calls "data collection plans", seems rather idiosyncratic-new to me were such things as "walk and talk" and the use of public meetings. This section could be better ordered to promote the actual methods rather than differences in the field location and grouping of participants. Additionally, I would contest his belief that content analysis can be qualitative as I cannot see how counting can be anything other than quantitativeregardless of what you are counting.

The insights into fieldwork experience are invaluable (chapter 7). Often methods books offer a systematic overview without furnishing us with insights into the actual hands-on process of conducting research. Similarly the chapter on ethics, brief as it is, is an important inclusion as it is a key consideration of any research project-but particularly so with the degree of personal contact with respondents one often gets when conducting qualitative research.

Minor quibbles with the book are that it has no index; an omission diminished by the excellent glossary and appendices. Frustratingly, the bibliography is a selection of books rather than all of those referred to in the text.

As a newcomer to the field, I was surprised at the dearth of qualitative research conveyed in papers at the 5th World Conference on Injury Prevention and Control (Delhi, 2000). This book hopefully marks a new era in our 
field, one that Jerry Moller has long called for, which will incorporate the "beliefs and behaviours of individuals and the social and cultural structure" (Moller quoted in Rothe, pxviii, and originally, Moller ${ }^{1}$ ) into accident prevention. Without it our understanding is that of the outsider; we fail to appreciate the intricate interplay of causes of unintentional accidents and injuries and in so doing, fail to make real headway to creating effective prevention strategies.

S GRUNDY Department of Child Health, University of Newcastle-upon-Tyne, UK

1 Moller J. Major issues and debates in injury control. Community based injury prevention. A practical guide. Canberra: The National Safety Council of Australia, 1992: 11.

\section{UPDATE ON ISCAIP}

\section{From the Chair of ISCAIP}

As many readers will be aware, the elections for the new ISCAIP Board were held in 2000 . I feel deeply honoured to have been elected Chair and wish to thank all concerned for their support. My colleagues on the Board are an outstanding team of highly respected injury prevention professionals and I am confident that we, together with the membership, can take ISCAIP into the new century with a renewed sense of purpose and urgency.

I want especially to record my appreciation of the incalculable contribution of Fred Rivara, founding Chair of ISCAIP, in laying the foundations of the organisation and in presiding over a smooth transition to the new regime. Fred's leadership has been truly inspirational and unlikely to be equalled in the foreseeable future. I am delighted to report that Fred has agreed to participate in ISCAIP Board discussions in his capacity as Immediate Past Chair and we look forward to his continuing involvement with the Society.

Since taking up the position, I have embarked on a steep learning curve. In its short life, ISCAIP has built up an impressive worldwide network of individual and corporate members all of whom are committed to the pursuit of the Society's goal, namely "To promote a significant reduction in the number and severity of injuries to children and adolescents through international collaboration".

Although progress is difficult to measure, ISCAIP's close identification with two key vehicles for international communicationInjury Prevention and the World Conference on Injury Prevention and Control-has been instrumental in ensuring that we are moving in the right direction. Under Barry Pless's wise editorship, the journal is now firmly established as the leading international peer reviewed publication in the field and its profound influence on the research community and service agencies around the world is widely acknowledged. The formal separation of ISCAIP from the journal did not, happily, sever the connection between the two, and the more recent broadening of the journal to include all ages has similarly caused no discernible turbulence in that mutually beneficial relationship. The Fifth World Conference on Injury Prevention and Control in New Delhi was, as always, heavily populated with ISCAIP members, some of whom attended a satellite meeting of the Society organised by our enthusiastic Asian representative. We are confident that the international organising committee for the next conference in Montreal in 2002 will be as keen as we are to continue the tradition and ensure a strong ISCAIP presence on that occasion also.

Perhaps I should try to spell out my own hopes and aspirations for ISCAIP. Our foremost strength lies in our potential to foster collaboration and I believe we should seek, through both electronic and conventional means, to develop this role further. Second, the membership of the Society represents an unsurpassed critical mass of expertise and (to use an old fashioned phrase) sapiential authority. Let's use our collective clout to maximise the effectiveness of injury prevention policies and practices in every corner of the globe through the dissemination of research based evidence and guidelines. Finally, the Delhi conference brought home to me (and I'm sure many others) just how dramatically different are the circumstances and obstacles faced by injury prevention professionals in India and other developing countries compared with the US, Europe, or Australia. Most ISCAIP members are all to well aware of this, of course, yet how many of us have found ways of coping constructively with the implications? Dinesh Mohan has called for the institution of imaginative collaborative projects between researchers working in low income countries (containing most of the world's population) and high income countries. ${ }^{1}$ Are injury prevention professionals ready to respond to this challenge? If so, how? Should we seek additional resources to oil the wheels of such "north-south" collaboration and, if so, where will we find them? I appeal to all readers of Injury Prevention to reflect on these questions and to try to articulate some answers. I can think of no more urgent task for ISCAIP-or indeed for the injury prevention community as a whole - in the 21 st century.

D H STONE

Chair, ISCAIP, Glasgow, Scotland

d.h.stone@clinmed.gla.ac.uk

1 Mohan D. Injury control and safety promotion: ethics, science and practice In: Mohan D, Tiwari G, eds. Injury prevention and control. London: Taylor \& Francis, 2000: 11.

\section{CALENDAR}

\section{0th Annual Conference on} International Safe Communities

21-23 May 2001, Anchorage, Alaska, USA. The theme is Safe Work, Safe Play Around the Clock. Further information and online registration: www.alaska-ipc.org or from Conference Manager, Diana Hudson, The Alaska Injury Prevention Center, PO Box 210736, Anchorage, Alaska, USA 99521-0736 (tel: +1 907929 3939, fax: +1 907929 3940, email: diana_hudson@hotmail.com).

\section{International Child Passenger Safety} Technical Conference

2-6 June 2001, Indianapolis, Indiana, USA. This conference will offer workshops on child passenger safety certification, boosters and belts for school age kids, legislation and advocacy, model law enforcement programs, restraint programs for children with special needs, transportation in other vehicles, and more. Professionals and volunteers from the field of transportation, engineering, public health, education, medical services, and insurance are invited to attend. Further information: International Center for Injury Prevention, www.cipsafe.org

\section{DETR Good Practice Conference}

20-22 June 2001, Bristol, UK. The DETR, the UK government department with responsibility for road safety, is staging this conference to disseminate good practice in road safety engineering and speed management, and to launch their good practice guidelines. Further information: Kevin Clinton, RoSPA, Road Safety Dept, Edgbaston Park, 353 Bristol Road, Birmingham B5 7ST, UK (tel: +44 (0)121248 2125, fax: +44(0)121248 2001).

\section{Nordic Safe Communities Conference}

21-24 August 2001, Denmark. Further information: Moa Sundeström, Karolinska Institutet, Department of Public Health Sciences, Division of Social Medicine, Norrbacka, SE-171 76 Stockholm, Sweden (tel: +468 517 77948, fax: +46 8 334693, email: moa.sundestrom@socmed.sll.se).

4th International PhD Course on Safety Promotion Research

17-29 October 2001, Stockholm. A course for researchers and $\mathrm{PhD}$ students in public health sciences and those interested in injury prevention and safety promotion research. Further information: Moa Sundeström, Karolinska Institutet, Department of Public Health Sciences, Division of Social Medicine, Norrbacka, SE-171 76 Stockholm, Sweden (tel: +46 8517 77948, fax: +468334693, email: moa.sundestrom@socmed.sll.se,web site: www.ki.se/phs/education).

\section{1st International Course on the Global Burden of Injury}

30 October-3 November 2001, Stockholm. The aim of the course is to provide a general scientific platform for the understanding of global trends and international differences in injury mortality and morbidity; for $\mathrm{PhD}$ and postgraduate students and senior researchers. Further information: Moa Sundeström, Karolinska Institutet, Department of Public Health Sciences, Division of Social Medicine, Norrbacka, SE-171 76 Stockholm, Sweden (tel: +46 8517 77948, fax: +46 8334693 , email: moa.sundestrom@socmed.sll.se, web site: www.ki.se/research/courses/postgrad_catalogue/ fall2000_en.html).

\section{6th World Conference on Injury Prevention and Control}

12-15 May, 2002, Montreal, Canada. The theme is "Injuries, Suicide and Violence: Building Knowledge, Policies and Strategies to Promote a Safer World". Further information: www.trauma2002.com, tel: +1 514 848 1133, fax: +1 5142886469 